\title{
Smart Grids and Their Role in Transforming Human Activities-A Systematic Literature Review
}

\author{
Ángeles Verdejo-Espinosa ${ }^{1}\left(\mathbb{D}\right.$, Macarena Espinilla-Estévez ${ }^{2, *(1)}$ and Francisco Mata Mata ${ }^{2}$ (D) \\ 1 Electrical Engineering Department, University of Jaén, 23071 Jaén, Spain; mverdejo@ujaen.es \\ 2 Department of Computer Science, University of Jaén, 23071 Jaén, Spain; fmata@ujaen.es \\ * Correspondence: mestevez@ujaen.es
}

Received: 9 September 2020; Accepted: 10 October 2020; Published: 19 October 2020

\begin{abstract}
In this work, a systematic review of the literature has been carried out to analyse the design of intelligent networks in environments inhabited by people and the applications of sensors to improve quality of life and aid human activities. This study aims to answer three research questions. The first question is whether the design of smart grids is made with people in mind. The second question focuses on whether intelligent networks are being taken account of in the research on human activity recognition, the Internet of Things, and the recognition of activities of daily living. The third question looks at whether there are synergies and multidisciplinary teams studying state-of-the-art technologies applied to environments inhabited by elderly or disabled people. Installations with sensors deployed for the improvement of the quality of human life will also help to improve the quality of the intelligent network, thus integrating the Human-Technology binomial. This study concludes with an analysis of the results of the sources examined, putting forward a protocol of seven proposals to guide future work.
\end{abstract}

Keywords: smart grids; sensors; human activity recognition; internet of things; literature review

\section{Introduction}

The design of electrical installations in a given environment poses a challenge for the improvement of energy management in our society. In the year 2019, one of the main objectives of the United Nations Climate Change Conference-COP25-held in Madrid was the development and transfer of technology to achieve a sustainable evolution of energy consumption worldwide, with the main objective of reducing greenhouse gas emissions [1].

Today, there is a growing need for society to take care of its health by integrating the use of technology and numerous studies and research efforts offer interesting works on this topic [2,3]. The technology that we design and build in intelligent environments must be a climate-focused technology; that is, technological developments must drive energy consumption through renewable sources, control and measure consumption, reduce greenhouse gas emissions, and alert and prevent inappropriate energy consumption. In short, household technologies should integrate the processes of energy efficiency and environmental sustainability.

Electrical and energy networks in general are designed, planned, and installed with the objective of providing high-quality electricity supply to users. This energy travels enormous distances to reach the final point, which is the consumer. People are essential in this scenario and play a key role in interacting with the energy networks when it comes to designing better installations and improving quality.

The Smart Grid is a modern intelligent network adapted to a new global paradigm. Intelligent systems bring together energy and information and communication technologies, improving performance, quality, generation, transmission, distribution, and marketing services $[4,5]$. 
Regarding the influence of intelligent networks in the transformation of human activities, it is essential to know the resources and systems of sensors, IoT and, in general, the devices that improve people's quality of life. Today, there is a growing need for society to take care of its health by integrating the use of technology. Human Activity Recognition (HAR) allows monitoring of people's quality of life and, in time, more features and functionalities emerge in this area, relying on a wide repertoire of hardware and software components. Proof of this is the implementation of several solutions in indoor environments, which capture the data generated from people's interactions with an intelligent environment [6]. Data collected from heterogeneous sensors implemented in intelligent environments or from sensors connected to the body (wearables) are stored in datasets [3] and the information obtained from intelligent devices is integrated into a larger set, the intelligent network that brings together an environment, a community, a city, and, in general, a joint strategy to improve the quality of technology and life in our society.

In 2010, the Conference of the Parties, the supreme decision-making body of the United Nations Framework Convention on Climate Change, established the Technology Executive Committee (TEC) with the objective of accelerating and enhancing the development and transfer of climate technology. This committee consists of 20 experts representing developed and developing countries. The Technology Executive Committee analyses climate technology issues and develops balanced policy recommendations, supporting countries to accelerate action on Climate Change (Figure 1). The Technology Executive Committee brings together a range of institutions, non-governmental organisations, government experts, the United Nations, and others [7].

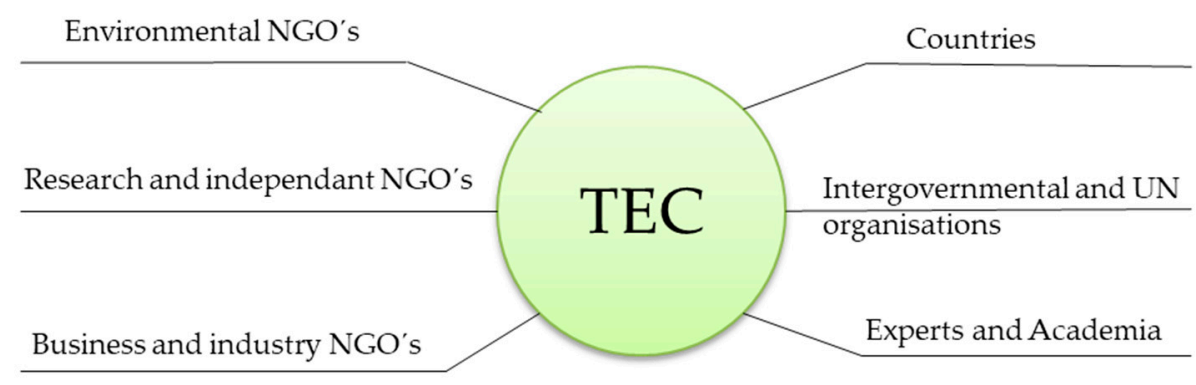

Figure 1. Focus areas of the Technology Executive Committee [7].

In 2018, the European Commission published the document: "A Clean Planet for all". A European strategic long-term vision for a prosperous, modern, competitive, and climate-neutral economy, in which it presented a strategy for the transition to a zero-net-emission economy in 2050. According to the European Commission, the energy system of the future will integrate the systems and markets for electricity, natural gas, air conditioning, and mobility, with smart grids that put citizens at the centre [8].

Technology, and its development, is not only an effective tool in the fight against climate change, but it is also an essential mechanism for the evolution of life on earth and the improvement of human health and the condition of the planet in general. Technological design in this context will be key to the future of humanity.

The technological design of the environments where we live, move, and work must also be the subject of a detailed analysis related to climate technology. Human beings produce and emit greenhouse gases as a product of our activity; hence we must design sustainable and efficient spaces.

The design of smart homes and houses must be adapted to existing regulations on electrical engineering and automation. These regulations have become obsolete and are sometimes not suitable for efficient and sustainable climate design. As is often the case, technological research and innovation are evolving faster than regulations $[9,10]$. Based on the above, in this work, we will focus on studying the interaction between intelligent systems integrated in human environments and the recognition of human activities that can be observed in such spaces in a multidisciplinary way, with the purpose 
of carrying out a systematic and comprehensive review of the existing research in this field and contributing new ideas to these advances [11,12].

This analysis aims to answer some of the following questions:

1. Is the design of Smart Grids (SGs) made taking into account the people living in homes or other spaces?

2. Based on the analysis of data from Human Activity Recognition (HAR) and Activities of Daily Living (ADL) systems, are the contributions in SGs being considered in these fields?

3. Are there synergies and multidisciplinary teams studying state-of-the-art technologies applied to environments inhabited by elderly or disabled people?

In order to try to answer the questions raised, firstly, a systematic analysis of the scientific literature in this field will be carried out and, secondly, a model will be proposed where people's quality of life and technology will be highlighted as necessary means to achieve the objectives of sustainable development, valuing sustainability and energy efficiency in all processes [13,14].

Based on the proposed research, the following actions will be undertaken:

- Analysing the research contributions on SGs and HAR. A systematic literature review will be carried out, applying specific criteria to search for patterns that interlink the Human-Technology binomial.

- Characterising and group the set of results obtained, performing an analysis of the proposals, methodology, relevance, and applications to intelligent environments.

- Proposing an action protocol with seven proposals to approach projects and designs in intelligent environments in which human activity prevails.

Among the analysed bibliography, numerous papers and research works related to SGs can be found [15-17], but if we narrow the search to SG systems applied to intelligent environments with sensors and HAR in indoor spaces, the number of works is considerably limited. As indicated in [3], with a large amount of data analysed, this research on HAR and its relationship with ADL resulted in a study that offered a magnificent analysis.

The objectives studied include: (1) Creating predictive models that allow the classification of normal and abnormal behaviour in people and (2) providing the necessary tools for the caregiver and the medical team to identify the activities performed by them and establishing preventive and corrective measures.

Our main objective is to carry out a systematic literature review that groups the advances in SGs and the use of sensors in home environments as a previous phase to researching the applications of human activity recognition with sensors to elderly people, people with disabilities, in care homes, inclusive and/or adapted environments, etc. All this, under the paradigm of achieving compliance with the sustainable development goals and the global strategy for the energy transition and climate change.

The work presented in this article contains the following sections: The introduction details the analysis of some basic issues that have prompted the research, as well as raising some questions and proposals that will be analysed in the following sections. In the research section, the sources that have served as reference for the work are studied. The third section explains the method and procedure used to extract, filter, and analyse the references and sources obtained in the systematic literature review. In the results section, a quantitative and qualitative analysis of the sources obtained is carried out and the data are detailed in tables and figures, as well as outlining and analysing the most important research works. Finally, the conclusions section explains the results obtained, answers the questions raised in the work, and lays out a protocol of recommendations for the future.

\section{Related Research}

By carrying out a study of references and scientific proposals on SGs, we can retrieve thousands of sources, most of them related to Smart Power Grids, Power Generation Systems, Electric Power Systems, Economy and Management of the Electric Network, and Control and Optimization of Electric 
Systems $[18,19]$. However, a list of SGs with sensors applied to the home limits the list of sources quite a bit.

We will focus our review on indoor environments to narrow down the sources that have developed similar research. By reviewing the related literature, we find sources that focus their research on the fields of the Internet of Things (IoT), SGs, Energy Engineering Computing, Wireless Sensor Networks, and Home Automation, among others.

We shall now highlight some of the studies found within these fields for their level of citations, their presence in high-impact journals or special relevance to the subject studied in this work.

Saha [20] describes trends in IoT, cloud computing, autonomous control, and artificial intelligence. This work discusses the need for synchronization of the Internet, wireless sensors, and actuators along with distributed computing to enable successful technologies for IoT. The regulatory aspect referred to here is interesting.

Other works [21] propose research on IoT applied to mobility, taking into account that this aspect is a human need and that there are many technological resources that can improve it, such as the use of sensors and intelligent devices in vehicles. In this work, we also include these sources, which are relevant to the study of SGs, since electric mobility is a basic factor in energy management, environmental sustainability, and, of course, to improve people's quality of life, especially vulnerable groups such as the disabled, the elderly, and others.

In [22], an overview is given of the wide variety of sensors applied to intelligent environments. It catalogues and classifies these according to uses and applications. Sensors applied to health, agriculture, environment, energy sources, among others, are analysed. The references to manufacturers, technologies, and future trends studied in this work are interesting. This work offers valuable information to advance in the study of sensors and their application in intelligent environments, taking into account climate change mitigation policies and the energy transition.

In relation to the hierarchical architecture of the intelligent network to evaluate the advantages of distributed data processing, one paper [23] offers a specific analysis of the sensors present in the home. In addition, local data processing is analysed through automatic learning algorithms integrated in the distributed system.

There are studies that integrate the design of sensors and HAR in applications whose purpose is energy or electricity demand control [24]. It is essential to study the response of stochastic demand in the smart grid considering the use patterns of random devices. An advance in this type of research will undoubtedly improve the quality of life of users [25]. User interactions, household appliances, and human activity recognition data and their relationship with household equipment are analysed. An automated method is proposed to determine when an electrical device is activated by household residents only from its energy trail.

The approach is interesting, since the interaction of people with the equipment is analysed through energy and consumption measurement. Data and consumption management are taken into account for the analysis of the efficiency and sustainability of the actions we study, an important vector for our analysis, since in our study we will consider the sustainable development goals and the challenge of the energy transition.

References and documentary sources from the Web of Science (WOS), Scopus, and IEEE Xplore databases have been carefully analysed according to the work methodology detailed as follows.

\section{Method}

There are numerous works that explore the systematic review of literature as a means to address research on a topic. In this paper, we have chosen this method since we find numerous references on SGs and HAR in intelligent environments and we want to delimit and analyse the results using both parameters, evaluated jointly. In this way, we intend to advance research that groups both vectors with the aim of improving future developments. Among the literature examined, we found work in 
the areas of engineering, as in [26], which is limited to finding which working models work best in numerous research studies, both qualitative and quantitative.

In studies such as [27], different works related to IoT and its applications are analysed. Generally, most of the works are focused on the field of health, medicine, oncology, etc. and references to the field of engineering greatly limit the scope of the research [28-33]. In some sources, the search was limited to two work vectors, as we have planned in this study, to subsequently establish the databases or search repositories chosen. The selection and exclusion of parameters were established as a strategic means to limit the sources, in order to focus the research as much as possible.

We established the following questions that we wanted to address in our work:

1. Does the design of Smart Grids (SGs) take into account the human vector? How many of the sources consulted on SGs research take into account the Human-Technology binomial to implement architectures, designs, and installations that respect people's quality of life and their environment?

2. In the analysis of data from HAR and ADL systems and the use of sensors for their monitoring, are SG contributions being considered to adapt and improve data acquisition, management in the monitoring of activities, and the implementation of sustainable development goals and the energy transition?

3. Are there synergies and multidisciplinary teams studying state-of-the-art technologies applied to environments inhabited by elderly or disabled people?

The databases we chose for the search are: IEEExplore, Web of Science, and Scopus (Table 1). We started searching for keywords and discarded any search parameters that were not relevant or could hinder our research. The search was limited to the time period 2015-2019 because developments in SG and HAR work in this field have been updated and advanced greatly in recent years. We limited the search to articles and conferences, discarding books, editorials, and essays. We focused on interior environments, homes, and indoor spaces, and therefore excluded outdoor or open spaces.

Table 1. Database sources.

\begin{tabular}{ll}
\hline Source & URL \\
\hline IEEE Xplore & http://ieeexplore.ieee.org \\
\hline Web Of Science (WOS) & http://apps.isiknowledge.com \\
\hline Scopus & http://www.scopus.com \\
\hline
\end{tabular}

We can see the search criteria and the filters applied in Table 2.

Table 2. Search strategies and filters.

\begin{tabular}{cc}
\hline Search for Keywords & Results \\
\hline “Smart Grids" and “Sensors" and “Home” & 481 \\
\hline Filters applied & 262 \\
\hline Filter 1: Time frame: 2015-2019 & 249 \\
\hline $\begin{array}{c}\text { Filter 3: Exclusion of some subject areas: smart meters, distributed } \\
\text { power generation, energy conservation and optimisation. }\end{array}$ & 180 \\
\hline Duplicates & 18 \\
\hline Total Results (180-18) & $\mathbf{1 6 2}$ \\
\hline
\end{tabular}

Figure 2 shows the search pattern used. As can be seen, the time frame selected is the last 5 years and some search terms related to energy management, electricity measurement, and distributed 
electricity generation, which are specific studies on energy systems and are not related to our objectives, were excluded.

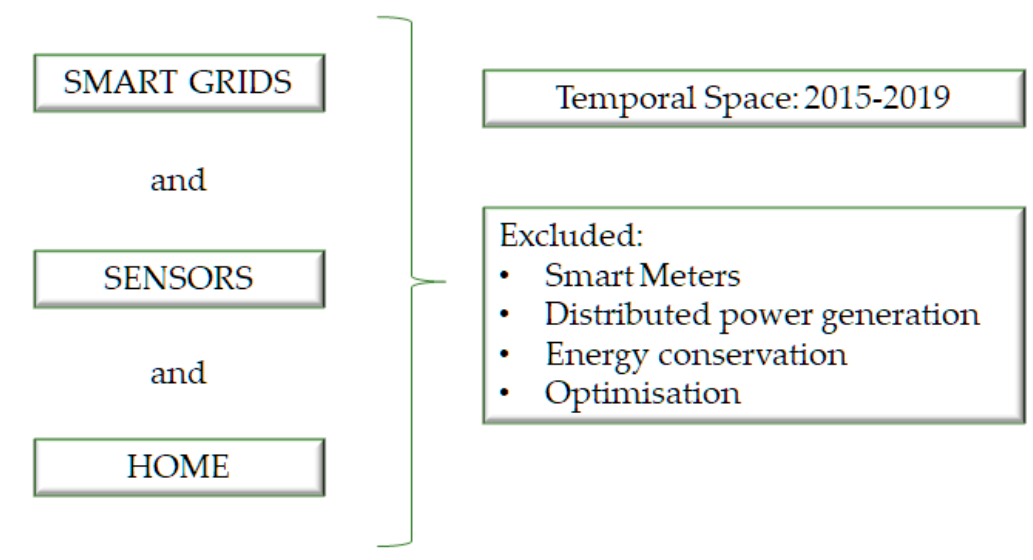

Figure 2. Search string model.

The following proposed search string was selected as it offered the most interesting results: (Smart Grids) and (Sensors) and (Home) and not (Smart Meters) and not (Distributed power generation) and not (Energy conservation) and not (Optimisation). In addition, the time frame and other specific vectors were selected by groups of articles, in order to discard any that were not relevant or did not offer any satisfactory results to the goals of the research effort.

Some indicators in the filtered works were also analysed, such as:

1. Type of environment analysed,

2. Whether it belongs to a research project and its results,

3. Whether the research is theoretical or experimental.

Data analysis was carried out with the help of data management, statistical, and graphic packages in order to present the results of the chosen sources. They were classified quantitatively, outlining the number of sources per year, number of citations, impact of the publication, and they were also presented qualitatively, indicating the most relevant conclusions, proposals for action, and implementation of results, etc.

\section{Results}

This section details the results of the selection process, including the search parameters that we analyse in Section 3, the filters that have been applied, the inclusion and exclusion indicators, and the duplicates in articles that exist in different databases.

\subsection{Quantitative Analysis}

We begin this point by indicating that a time frame of full years has been chosen, from 2015 to 2019. In the year 2020, at the date of completion of this work, there are some very interesting references related to our research, but because they do not comply with the time parameter, they have not been included in the data tables and quantitative and qualitative analyses. A total number of 29 works that could meet the objectives of this research have been located in the databases analysed. The work done by Dileep can be highlighted [34], as it offers a comprehensive and detailed analysis of all the components of the intelligent network, its applications, benefits, and opportunities, also taking into account the importance of the users.

We continue analysing Table 3, where it can be seen that 481 results were obtained in the first block of data extraction, while applying the corresponding filters resulted in a lower number, 180 results. The first column indicates the name of the analysed database, the second column, Results, 
indicates the number of gross results obtained. The columns for Filter 1, Filter 2, and Filter 3 present the screening results. In the last column, Revised Results, all 180 results are included.

Table 3. Summary of search results and filters.

\begin{tabular}{lccccccccc}
\hline & Library & Results & Filter 1 & Filter 2 & Filter 3 & $\begin{array}{c}\text { Revised } \\
\text { Results }\end{array}$ & Duplicates & $\begin{array}{c}\text { Revised Results } \\
\text { Final }\end{array}$ \\
\cline { 2 - 9 } $\begin{array}{l}\text { Search } \\
\text { String } \\
\text { Model }\end{array}$ & IEEExplore & 129 & 74 & 72 & 0 & 72 & $\begin{array}{c}\text { IEEExplore + WOS } \\
+ \text { SCOPUS }\end{array}$ & 3 \\
\cline { 2 - 9 } & WOS & 34 & 23 & 22 & 0 & 22 & IEEExplore + WOS & 9 \\
& SCOPUS & 318 & 165 & 155 & -69 & 86 & $\begin{array}{c}\text { IEEExplore + } \\
\text { SCOPUS }\end{array}$ \\
\hline Total & & 481 & 262 & 249 & -69 & 180 & & 18 \\
\hline
\end{tabular}

By filtering out the works that are repeated over several databases, we obtain the final number of articles to be reviewed in a qualitative way, this being 162 .

As we can see in Figure 3, representing the results from the Scopus database, there is a remarkably large percentage of articles in the areas of Computer Science (41.1\%) and Engineering (35.9\%). These data coincide approximately with those of the WOS and IEEExplore databases.

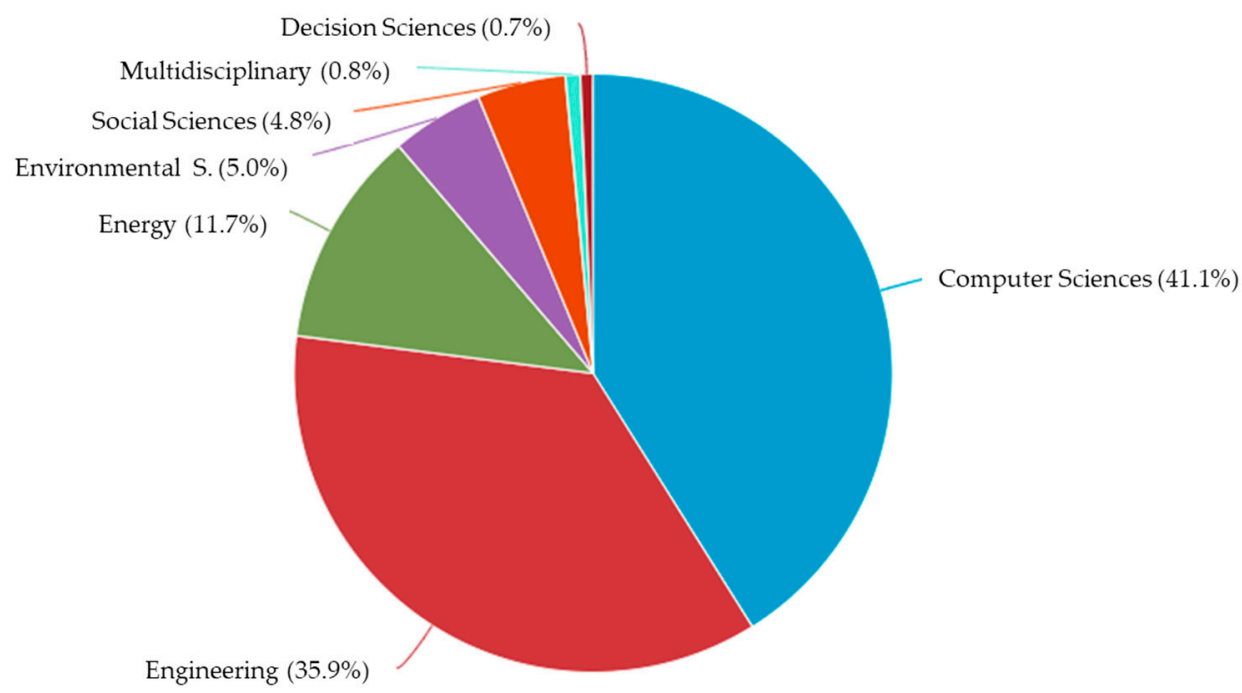

Figure 3. Analysis of the Scopus database results by area.

In the quantitative analysis of the final results, we can observe that there are some works that are out of the scope of what we want to analyse and that were not detected in the previous screening. With a more in-depth review of each one of them, they were discarded from our work. Therefore, the final number of works in our quantitative analysis is 162 .

We observe in Tables 4-6, according to the databases analysed, that the results differ according to type of publication source, year, and number of publications. Thus, in the IEEExplore database, we see that most of the research is published in international conferences $(77.8 \%)$ and there is a greater number of publications in 2017 and 2018. We can see this in Table 4.

It can be deduced from Table 5 that most publications are made in high-impact journals, although this subject is also dealt with by other, lesser publications. Although, we continue to see that a very high number of the sources are published in international conferences and congresses. 
Table 4. Quantitative results from the IEEExplore database.

\begin{tabular}{|c|c|c|c|c|c|c|c|}
\hline \multirow{2}{*}{ IEEExplore Library } & \multirow{2}{*}{ Publications } & \multirow{2}{*}{$\%$} & 2019 & 2018 & 2017 & 2016 & 2015 \\
\hline & & & $12.5 \%$ & $27.8 \%$ & $26.4 \%$ & $16.7 \%$ & $16.7 \%$ \\
\hline IEEE Sensors Journal & 7 & 9.7 & 1 & 2 & 2 & 1 & 1 \\
\hline IEEE Access & 2 & 2.8 & 1 & & 1 & & \\
\hline IEEE Communications Surveys \& Tutorials & 1 & 1.4 & & 1 & & & \\
\hline $\begin{array}{l}\text { IEEE Transactions on Green Communications } \\
\text { and Networking }\end{array}$ & 1 & 1.4 & & & 1 & & \\
\hline $\begin{array}{l}\text { IEEE Transactions on Multi-Scale } \\
\text { Computing Systems }\end{array}$ & 1 & 1.4 & & & 1 & & \\
\hline $\begin{array}{l}\text { Canadian Journal of Electrical and } \\
\text { Computer Engineering }\end{array}$ & 1 & 1.4 & & 1 & & & \\
\hline IET Generation, Transmission \& Distribution & 1 & 1.4 & & & & & 1 \\
\hline IEEE Internet of Things Journal & 1 & 1.4 & & & & & 1 \\
\hline IEEE Transactions on Education & 1 & 1.4 & & & & & 1 \\
\hline International Conference & 56 & 77.8 & 7 & 16 & 14 & 11 & 8 \\
\hline Total & 72 & 100 & 9 & 20 & 19 & 12 & 12 \\
\hline
\end{tabular}

Table 5. Quantitative results of the Web of Science (WOS) database.

\begin{tabular}{|c|c|c|c|c|c|c|c|}
\hline \multirow{2}{*}{ WOS Library } & \multirow{2}{*}{ Publications } & \multirow{2}{*}{$\%$} & \multirow{2}{*}{$\begin{array}{c}2019 \\
55.6 \%\end{array}$} & \multirow{2}{*}{$\begin{array}{l}2018 \\
11.1 \% \\
\end{array}$} & \multirow{2}{*}{$\begin{array}{c}2017 \\
33.3 \%\end{array}$} & \multirow{2}{*}{$\begin{array}{l}2016 \\
0.0 \%\end{array}$} & \multirow{2}{*}{$\begin{array}{l}2015 \\
0.0 \%\end{array}$} \\
\hline & & & & & & & \\
\hline IEEE Sensors Journal & 2 & 22.2 & & 1 & 1 & & \\
\hline IEEE Access & 1 & 11.1 & 1 & & & & \\
\hline IEEE Instrumentation \& Measurement Magazine & 1 & 11.1 & 1 & & & & \\
\hline Information Sciences & 1 & 11.1 & 1 & & & & \\
\hline IET Networks & 1 & 11.1 & 1 & & & & \\
\hline Physical Communication & 1 & 11.1 & & & 1 & & \\
\hline IEEE Transactions on Multi-Scale Computing Systems & 1 & 11.1 & & & 1 & & \\
\hline \multicolumn{8}{|l|}{ IEEE Communications Surveys \& Tutorials } \\
\hline \multicolumn{8}{|l|}{$\begin{array}{l}\text { IEEE Transactions on Green Communications } \\
\text { and Networking }\end{array}$} \\
\hline \multicolumn{8}{|l|}{$\begin{array}{l}\text { Canadian Journal of Electrical and } \\
\text { Computer Engineering }\end{array}$} \\
\hline \multicolumn{8}{|l|}{ IET Generation, Transmission \& Distribution } \\
\hline \multicolumn{8}{|l|}{ IEEE Internet of Things Journal } \\
\hline \multicolumn{8}{|l|}{ IEEE Transactions on Education } \\
\hline International Conference & 1 & 11.1 & 1 & & & & \\
\hline Total & 9 & 100 & 5 & 1 & 3 & 0 & 0 \\
\hline
\end{tabular}

As with the aforementioned databases, the quantitative results of the number of publications in Scopus are shown in Table 6 according to the title of the journal or international conference. The publication percentages per year are also outlined, in which we can see that they are very similar. With regard to the type of publication sources, $52 \%$ of works have been published in international conferences and the rest in journals.

In Table 7, it can be seen that the main thematic areas in which the works have been published are largely concentrated in the fields of Engineering (30\%) and Computer Science (28\%). Nevertheless, some of the sources have been published over a notable and wide group of research areas, such as environmental sciences or social sciences. 
Table 6. Quantitative results of the Scopus database.

\begin{tabular}{|c|c|c|c|c|c|c|}
\hline \multirow{2}{*}{ SCOPUS Library } & \multirow{2}{*}{ Publications } & 2019 & 2018 & 2017 & 2016 & 2015 \\
\hline & & $17.4 \%$ & $19.8 \%$ & $17.4 \%$ & $23.3 \%$ & $22.1 \%$ \\
\hline ACM Transactions on Sensor Networks & 1 & & & & & 1 \\
\hline Applied Energy & 1 & 1 & & & & \\
\hline Applied Soft Computing Journal & 1 & & & 1 & & \\
\hline Applied Thermal Engineering & 1 & & & & & 1 \\
\hline ARPN J. of Engineering and Applied Sc. & 1 & & & 1 & & \\
\hline Canadian J. of Electrical and Comp. Enginee. & 1 & & 1 & & & \\
\hline Computer Communications & 1 & & & 1 & & \\
\hline Computer Networks & 1 & & & & & 1 \\
\hline Computers and Electrical Engineering & 1 & 1 & & & & \\
\hline Electronics & 2 & 1 & 1 & & & \\
\hline Energy and Buildings & 1 & & & & 1 & \\
\hline Energy Research and Social Science & 1 & & & & & 1 \\
\hline IEEE Consumer Electronics Magazine & 1 & 1 & & & & \\
\hline IEEE Internet of Things Journal & 1 & & 1 & & & \\
\hline IEEE J. on Selected Areas in Communic. & 1 & & & & & 1 \\
\hline IEEE Transactions on Education & 1 & & & & & 1 \\
\hline IEEE Transactions on Green Comm. and Net. & 1 & & & 1 & & \\
\hline IEEE Transact. on Multi-Scale Comp. Systems & 1 & & & 1 & & \\
\hline IEEE Transactions on Smart Grid & 1 & & & & & 1 \\
\hline IEEE Wireless Communications & 1 & & & 1 & & \\
\hline Information (Japan) & 1 & & & & & 1 \\
\hline Information Fusion & 1 & 1 & & & & \\
\hline Internat. J. of Applied Engineering Research & 1 & & & & & 1 \\
\hline Intern. J. of Comm. Netw. and Inform. Security & 1 & & 1 & & & \\
\hline Internat. J. of Comp. Netw. and Comm. & 1 & & & & 1 & \\
\hline Internat. J. of Control Theory and Applic. & 1 & & & & 1 & \\
\hline Internat. J. of Cooper. Informat. Systems & 1 & & & & 1 & \\
\hline Internat. J. of Grid and Distrib. Computing & 1 & & 1 & & & \\
\hline Internat. J. of Recent Technology and Engin. & 1 & 1 & & & & \\
\hline Jisuanji Y. Fazhan/Comp. Research and Dev. & 1 & & & & 1 & \\
\hline Journal of Communications & 1 & & & & & 1 \\
\hline Journal of Internet Services and Applic. & 1 & & 1 & & & \\
\hline Journal of Network and Comp. Applications & 1 & 1 & & & & \\
\hline Physical Communication & 1 & & & 1 & & \\
\hline Procedia Manufacturing & 1 & & & & & 1 \\
\hline Recent Patents on Engineering & 1 & & & 1 & & \\
\hline Sustainability (Switzerland) & 1 & & 1 & & & \\
\hline Sustainable Energy, Grids and Networks & 1 & & 1 & & & \\
\hline Wireless Personal Communications & 1 & 1 & & & & \\
\hline Wireless Personal Communications & 1 & & & & & 1 \\
\hline International Conference & 45 & 7 & 9 & 7 & 15 & 7 \\
\hline Total & 86 & 15 & 17 & 15 & 20 & 19 \\
\hline
\end{tabular}


Table 7. Main thematic areas of publication.

\begin{tabular}{lc}
\hline Thematic Areas & $\%$ \\
\hline Engineering & $30 \%$ \\
\hline Computer Science & $28 \%$ \\
\hline Energy & $9 \%$ \\
\hline Mathematics & $7 \%$ \\
\hline Physics and Astronomy & $7 \%$ \\
\hline Social Sciences & $3 \%$ \\
\hline Biochemistry, Genetics and Molecular Biology & $2 \%$ \\
\hline Business, Management and Accounting & $2 \%$ \\
\hline Chemistry & $2 \%$ \\
\hline Decision Sciences & $2 \%$ \\
\hline Environmental Science & $2 \%$ \\
\hline Materials Science & $2 \%$ \\
\hline Economics, Econometrics and Finance & $1 \%$ \\
\hline Medicine & $1 \%$ \\
\hline Pharmacology, Toxicology and Pharmaceutics & $1 \%$ \\
\hline
\end{tabular}

Figure 4 shows the total percentage of documents per area. As we can see, there is a remarkably large percentage of articles in the areas of Computer Science (27.9\%) and Engineering (30.2\%).

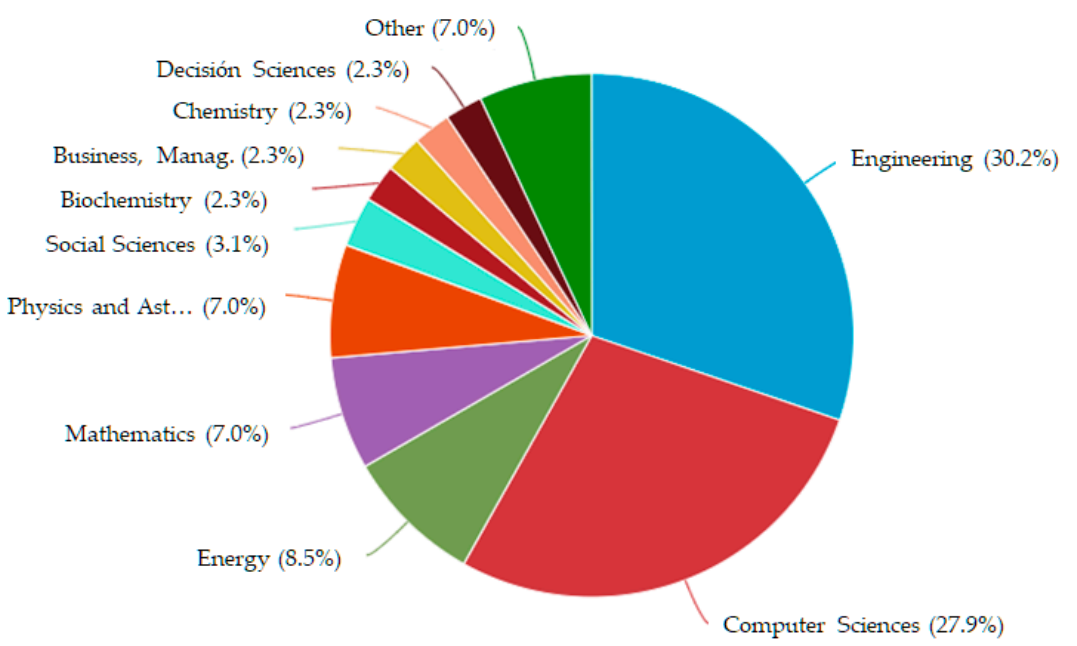

Figure 4. Percentage total of documents by area.

In Figure 5, we can see the origin of the authors of the analysed works. The country that covers the highest number of sources is India, followed by the United States, China, South Korea, Canada, France, and Italy.

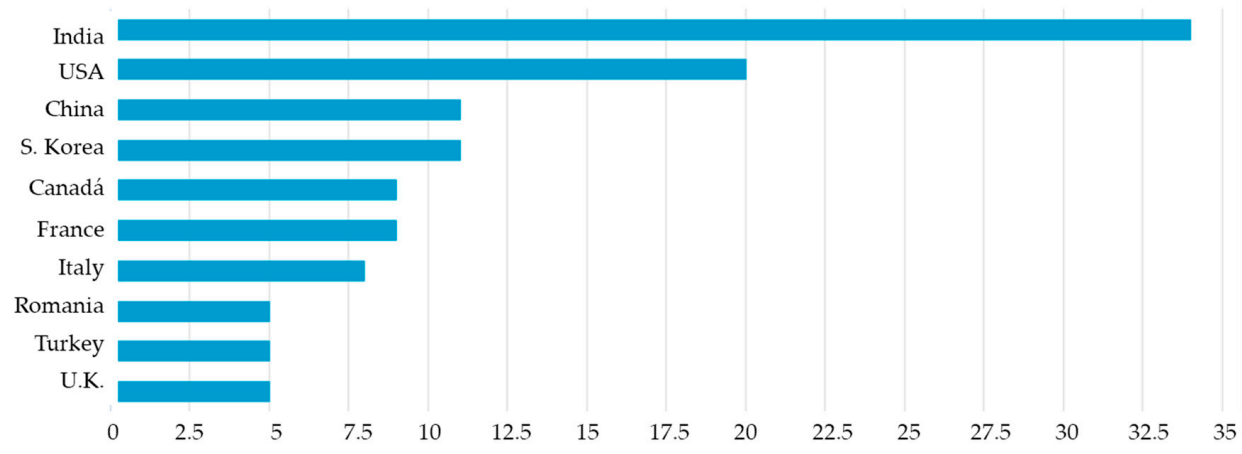

Figure 5. Number of documents by country of authors. 


\subsection{Qualitative Analysis}

According to the quantitative extraction, we have a set of 162 documents to analyse. We look at each of them in detail and have excluded those that do not provide relevant information to our research, since the study of SGs and their relationship with sensors and the home means that there are some works that fall outside of the scope of our discussion.

As stated in the objectives of the work laid out in Section 1, we will carry out a systematic literature review that groups the advances in SGs and at the same time details the use of sensors in the home as an initial research model in the applications of human activity recognition with sensors in elderly people, people with disabilities, applications to residences, inclusive and/or adapted environments, etc. All this, under the paradigm of achieving compliance with the sustainable development goals and the global strategy of the energy transition and climate change.

Only three of the sources analysed thoroughly study the relationship between SGs and HAR, as we have analysed by reading the sources that have been selected on the basis of the systematic literature review. This first analysis leads us to a first point for the conclusions of this study, which is the fact of the scarce relation that we find in the strategy of studies and advances in SGs with the energy transition and the Human-Technology binomial. It can be clearly seen that in engineering, technology, and SG studies, the human being is understood as one more vector of analysis and not as the main vector on which research and the study matrix of these works should be based.

Table 8 specifies the type of publication and the references and topics in each research work that are related to SG analysis and strategy, sensor use techniques, and type of application to the home. In this way, we have grouped the sources by topic, similarly to the one used in the databases to select the references.

The analysis of each of the sources has been carried out in an in-house database, indicating the following parameters:

- Identification of the source with bibliographic reference,

- Journal or conference where it is published,

- Title, year, and area of knowledge.

- Proposed research tools and techniques.

- Technologies and synergies that interrelate SGs with sensors and the home.

- Applications for the elderly and people with disabilities.

Table 8. List of most cited sources by subject and database.

\begin{tabular}{|c|c|c|c|}
\hline Strategies and Topic & WOS & IEEE Xplore & Scopus \\
\hline $\begin{array}{l}\text { Analysis of architectures, models, prototypes and } \\
\text { studies on the Smart Grid and its relationship with } \\
\text { communication systems for the automation of } \\
\text { low-voltage electrical networks in intelligent } \\
\text { indoor environments }\end{array}$ & [35-42] & {$[43,44]$} & [45-50] \\
\hline $\begin{array}{l}\text { 2. Control theory modelling. Mathematical analysis, block } \\
\text { diagrams, differential/integral equations, etc. } \\
\text { are included }\end{array}$ & [51] & [52-55] & [56-60] \\
\hline 3. Smart Grids and their application to HAR and ADL & [61] & {$[62,63]$} & \\
\hline $\begin{array}{l}\text { 4. Simulation of intelligent environments with sensors in } \\
\text { the home. Data control architecture, complex } \\
\text { computer systems }\end{array}$ & [64-66] & {$[60,67-83]$} & {$[81,84-86]$} \\
\hline
\end{tabular}


Table 8 shows the different themes and research strategies analysed, according to the database and the subject matter.

The strategies analysed are listed below:

1. Analysis of architectures, models, prototypes, and studies on SGs and their relationship with communication systems for the automation of low-voltage electrical networks in intelligent indoor environments.

2. Control theory modelling. Mathematical analyses, block diagrams, differential/integral equations, etc., are included.

3. SGs and their application to HAR and ADL.

4. Simulation of intelligent environments with sensors in the home. Data control architecture, complex computer systems.

We can observe that, according to the qualitative analysis in Table 8, a very small number of sources that coincide with the search strategy linking SGs to sensors and home environments and with research based on HAR and ADL are repeated in all the databases analysed.

Different issues have been detected that will lead us to draw up an action protocol and work model that can serve as a basis for design teams in engineering, architecture, institutions, etc., where it is paramount that studies on SGs place their focus on people as the backbone of all research.

If we analyse the relevance of the sources in which the works have been published, we see in Table 9 that most common destination country for the publications is the United States of America (USA).

Table 9. Sources with the most publications and highest impact.

\begin{tabular}{|c|c|c|c|c|}
\hline SOURCE & Publications & Country & ISSN & Quartile \\
\hline IEEE Sensors Journal & 7 & USA & $1558-1748$ & Q1-Q2 \\
\hline IEEE Int. Conf. on Smart Grid Communicat. & 6 & USA & 2016 & - \\
\hline Inter. Istanbul Smart Grids and Cities Cong. & 3 & USA & $7281-1315$ & - \\
\hline IEEE Access & 2 & USA & $2169-3536$ & Q1 \\
\hline Electronics & 2 & SWITZ. & $2079-9292$ & Q3 \\
\hline IEEE Communications Surveys \& Tutorials & 1 & USA & $1553-877 X$ & Q1 \\
\hline IEEE Trans. on Green Commun. and Network. & 1 & USA & $2473-2400$ & - \\
\hline IEEE Trans. on Multi-Scale Comp. Systems & 1 & USA & $2332-7766$ & Q1-SJR \\
\hline Canadian J. of Electrical \& Comp. Engineering & 1 & CANADA & 0840-8688 & Q3 \\
\hline IET Generation, Transmission \& Distribution & 1 & UK & $1751-8687$ & Q2 \\
\hline IEEE Internet of Things Journal & 1 & USA & $2327-4662$ & Q1 \\
\hline IEEE Transactions on Education & 1 & USA & 0018-9359 & Q2 \\
\hline Information Sciences & 1 & USA & 0020-0255 & Q1 \\
\hline IET Networks & 1 & UK & 20474962 & Q2 SJR \\
\hline ACM Transactions on Sensor Networks & 1 & USA & $1550-4859$ & Q2 \\
\hline Applied Energy & 1 & UK & 0306-2619 & Q1 \\
\hline Applied Soft Computing Journal & 1 & NETHERL. & 15684946 & Q1 \\
\hline Computers \& Electrical Engineering & 1 & UK & $0045-7906$ & Q2 \\
\hline
\end{tabular}

If we analyse some of the most cited or relevant works, we will be able to structure and examine which are the most studied trends and research parameters and also the references and other documents that have been used by these sources. We will focus mainly on the most recent works. 


\subsubsection{Analysis Strategy 1. SG Architectures, Models and Studies}

There are numerous sources that propose their work as an analysis of architectures, models, prototypes, and studies on SGs and their relationship with communication systems for the automation of low-voltage electrical networks in intelligent indoor environments.

If we analyse the documents [35-42,46], we find relationships between the fields of work studied. For example, a multi-zone control scheme for data and energy flow management was designed and evaluated in [35] using real data on load demand and energy prices from the household power grid. A reduction in energy demand was deduced.

In [36], a target optimization technique was proposed and the proposed algorithm coordinates all monitored and recorded appliances for better use of electrical energy by means of sensors. The proposed method was tested and verified using 300 (household) case studies. In [37], an in-depth analysis of university training related to SGs, sensors, and their practical applications is presented in a study with engineering students. A framework for defining resilience in power systems is proposed in [38], which divides the ways in which the system supports extreme disturbance events into two categories: Disturbance absorption and disturbance recovery. Resilience is a multidimensional property of the electric grid; it requires managing disturbances originating from physical component failures, cyber component malfunctions, and human attacks. It is based on a qualitative risk assessment study in SGs.

In [39], an algorithm is analysed using real residential energy consumption data from the database, which allows the consumer to compare their energy consumption with that of their neighbours or detect any anomalies, such as a faulty appliance. Consumers can also be classified into different groups, which can be used effectively to improve demand response policies.

In [40], a systematic literature review is carried out on the energy management systems for the home implemented over the last five decades. It analyses the home automation protocols integrated in the home. The model proposed by the authors facilitates the change of role from a passive user to an active user in the electrical energy value chain to control, monitor, and supervise any household appliance in real time, remotely or directly. In [42], a range of changes in the electric-electronic industry regarding the growth of SG automation and sensor technology is explored. Market trends in the electronics industry in the coming years were analysed.

In the IEEExplore database, some works in the field of SGs, sensors, and applications in the intelligent home have been selected to be studied [43,44]. In [43], educational training in SGs and the use of advanced sensor technologies are analysed. This document presents a test bed in the smart home based on the project-based learning (PBL) pedagogical model for undergraduate education. The proposed test bench enables undergraduate students to gain key skills in smart network-related topics such as peak demand flattening, real-time price response, wireless sensor networks, machine learning, pattern recognition, embedded system programming, user interface design, circuit, and database design.

In [44], we found a very interesting work framed within a special issue of a high-impact publication and related to SGs, sensors, and their implementation in intelligent environments. For example, different sensors and their applications to smart cities are studied regarding the measurement, control, and management of energy. Some of the most cited articles in this special issue look into smart metering and its role in the IoT of the future. In this special issue, other topics are also analysed, and Morello proposes the development and experimental validation of a smart power meter capable of monitoring power in real time. Its approach is based on technologies, applications, demand management, models, and prototypes related to energy.

There is some interesting research in the Scopus database, where [45] proposes a new energy management approach to smart homes that combines a wireless network based on Low-Energy Bluetooth (BLE) for communication between home appliances with a Home Energy Management (HEM) scheme. People's comfort is taken into account when it comes to intelligent and integrative energy management. Figure 6 shows a proposal for a home network with sensors based on Bluetooth. 


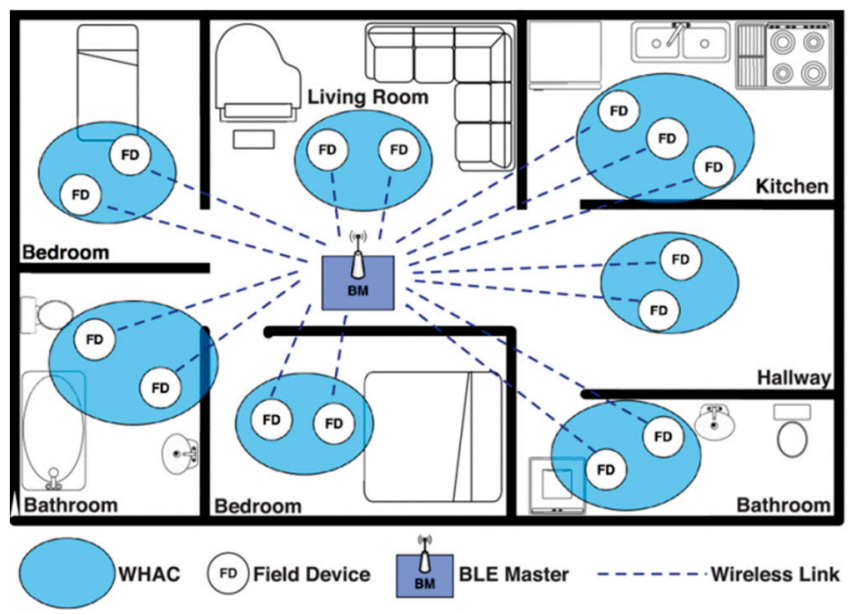

Figure 6. Proposal for a home network with sensors based on Bluetooth [45].

In [50], a decentralized algorithm for demand scheduling that minimizes consumer discomfort and the cost of electricity in a home is studied. In this paper, they differentiate smart home devices as non-programmable and programmable. The first refers to devices with a fixed energy requirement that are not subject to programming decisions (TV, refrigerators, modems, etc). Programmable appliances allow the use of the appliance to be changed over time and have a direct relationship with consumer preferences and behaviour (dishwashers, washing machines and dryers).

In [87], intrusive sensors directly connected to the monitored devices are used. This work classifies the connected devices into four categories and displays the sequences. In [47], similarly to other documents, a model for energy evaluation and management in intelligent homes is explored, with the integration of sensors in devices and appliances. A way to reduce the energy of ZigBee-based smart appliances and meters for SGs is proposed.

\subsubsection{Analysis Strategy 2: Modelling Control Theory, Mathematical Analysis, Block Diagrams,} Differential/Integral Equations

If we propose an analysis of the works that contain research on control theory modelling, mathematical analysis, etc., that are an essential part of developments in the field of study of SGs concerned with integrated sensors in the home, we find the following references that carry out similar studies: [51-60].

In [52], an algorithm for the evaluation of different scenarios is developed. The proposed algorithm also considers devices, external environmental parameters, and human behaviour. In this model and simulation, human aspects in the field of energy consumption are taken into account.

One interesting aspect that needs to be addressed is that which is referred to in [53] and which in this era has grown considerably-the field of cyber security. In this document, we analyse IoT-enabled cyberattacks, which can be found in all fields of application.

Three objectives are proposed: (1) To evaluate IoT-enabled cyberattacks with a risk-based approach, (2) to identify hidden and subliminal attack routes enabled by IoT against critical infrastructures and services, and (3) to examine mitigation strategies for all fields of application. In analysing SGs and their application to HAR, we must take cyber security into account.

In [59], a protocol to help minimise security breaches that may occur in systems with HAR sensors and applications is discussed. The emergence of IoT and the availability of low-cost sensor platforms and devices capable of wireless communications enables a wide range of applications, such as intelligent home and building automation, mobile healthcare, intelligent logistics, distributed monitoring, SGs, energy management, etc. These devices are expected to employ the restricted application protocol for the integration of such applications with the Internet, which includes the link of the user protocol with the datagram transport layer security protocol to provide end-to-end security. 
In [55], a cost-effective appliance programming model for residential users is presented and aims to optimise the operating time of appliances.

Wazid [56] studies a new efficient protocol for remote user authentication in the implementation of IoT and also evaluates the formal security verification of the scheme by automatically validating the Internet Security Applications and Protocols Tool (AVISPA) through simulation to verify whether it is secure (Figure 7).

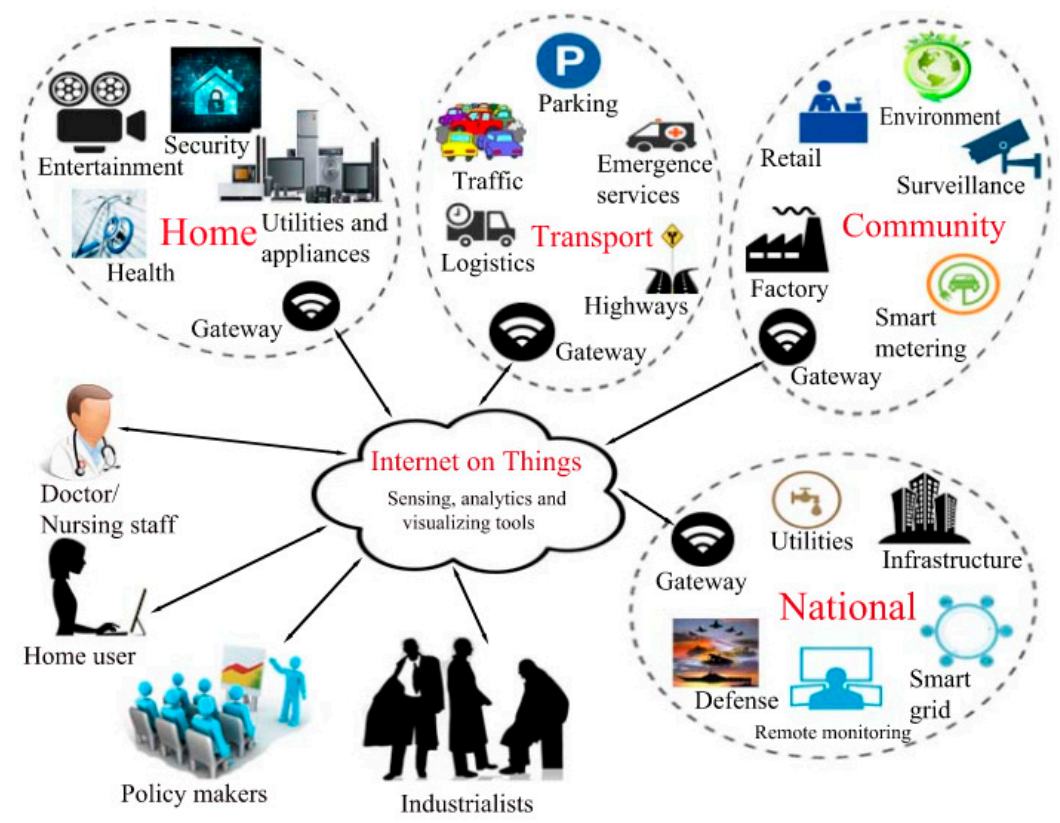

Figure 7. Network architecture Internet of Things (IoT) [56].

In [58], the case of SGs applied to electrical networks and communication protocols is studied. This is also the case in [60], where the main objective is data analysis and prediction of power grid demand models.

\subsubsection{Analysis Strategy 3: SGs and Their Application to HAR and ADL}

The results of a study carried out in 19 Scottish households in which energy consumption and the perception of SGs in relation to energy were controlled by means of sensors and equipment installed in these homes, mainly in homes inhabited by older people, are presented in [61]. This applies a social scope to the study, a case that interests us, since one of the objectives of the work we are analysing is social involvement, applying the study and its results to households and elderly people in future applications.

In [62], an intelligent network architecture based on an IoT platform that can host a wide range of applications for the smart home is presented. The proposal is "customer-centric", rather than "distribution-centric", in the sense that it favours ease of implementation and user acceptance, taking advantage of the smart home trend to allow the merger of smart networks and smart home applications.

In reference [63], an analysis of civil applications, prototypes, and possibilities for future integration of the wireless sensor is carried out by means of a bibliographic review, discussing human life and welfare. It classifies the use of wireless sensors in different disciplines and makes specific mention of those related to human health and human use for HAR.

We can observe that in the filtering of documents and research works, in this case for studies related to SGs, sensors, and devices that facilitate, study, or research human activities, mobility in intelligent environments, etc., we find few works that interrelate these subjects. 
We would have to apply other search parameters to find further research in this field, but we wanted to analyse the fact of direct studies with people, with mobility within the home of people with disabilities, elderly people, and other types of search vectors being largely absent when searching for the terms SGs or intelligent networks.

This will lead us to the conclusion presented at the end of the work, in which we analyse this fact.

4.2.4. Analysis Strategy 4: Simulation of Intelligent Environments with Sensors in the Home, Data Control Architecture, Complex Computer Systems

In [67], the relationship of SGs assisted by IoT is addressed: Technologies, architectures, applications, prototypes, and directions for future research. It is an interesting and comprehensive work on the more specific field of SGs and their relationship with IoT (Figure 8). However, we still do not see a more direct relationship with the social and human spheres, in order to link this SG strategy with its direct application to HAR and ADL. In this work, the research is focused on structuring the sources of SGs and their relationship with IoT, but it covers a large number of vectors related to the generation, transmission, and marketing of electrical energy, where the home and the application of sensors for the improvement of people's quality of life is scarcely touched upon.

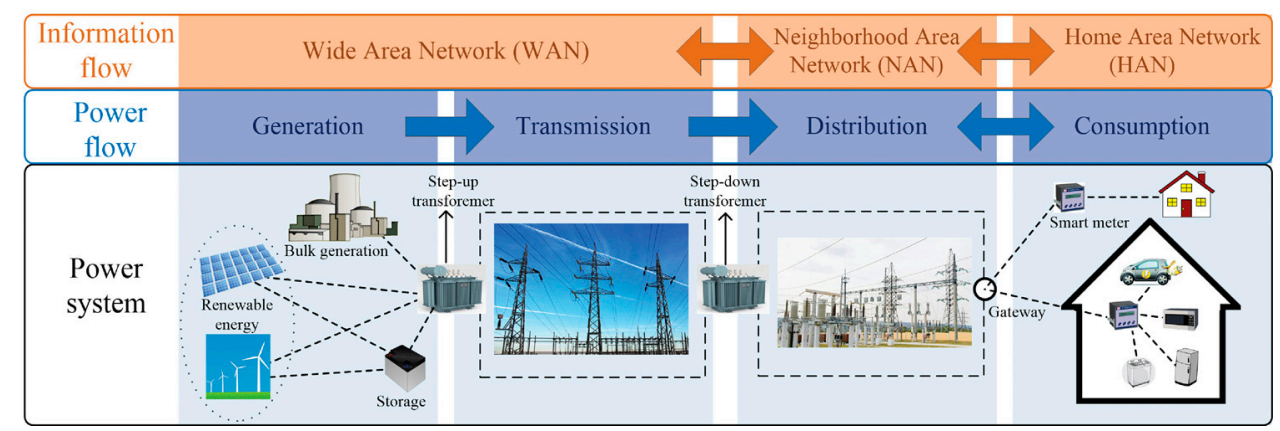

Figure 8. Smart Grid architecture featuring power systems, power flow, and information flow [67].

Data privacy and security for the home area network connected to the network using IoT is discussed in [64]. This paper looks into secure data flow and customer data privacy during critical and emergency operations. Data are available in real time with minimal delay in transit time. Devices are continuously monitored for vital and emergency services. User energy consumption data are intended to be available in the cloud and also on customized electronic devices in real time.

Aroua [68] proposes a new framework for household energy control in smart homes using Cognitive Radio Sensor Networks (CRSN).

Andrade, in his work [65], develops a management methodology that analyses the behaviour of wireless networks within an intelligent home through a simulation, taking into account several parameters or restrictions such as coverage distance and capacity. The smart grid infrastructure is described, and a mathematical model is proposed to minimise the distance of the sensors to the access points within the area under consideration.

In [70], optimal energy demand data management for smart homes is studied. The system can support near real-time decisions for 10,000 customers, each of which has 10 sensors with only 35 basic machines running free software in the cloud.

The European project COMPOSE [66], Collaborative Open Market to Place Objects at your Service, analysed the inclusion of sensors inside a supermarket that track the location of shopping carts as customers move through the store, which can then be combined with shopping information. These data can be used to help position the product on the supermarket shelves. This type of research does provide learning to be implemented in the development of HAR studies, however this document does not discuss this aspect, but focuses rather on business production. 
The review of communication protocols or algorithms, which study the design and implementation of environments with SG sensors and to a large extent are studies in the field of energy demand, electrical networks, are an important area of research among the following documents analysed: [73-77].

There are also studies that address the role of 5G technology in the IoT [78] and in some others, such as [84], different vectors are studied, such as temperature and $\mathrm{CO}_{2}$ level and its control, to find out how people move around in a home or how they consume. This study developed a methodology to determine individual household occupation patterns using ubiquitous household sensors.

The characteristics were derived from sensors that monitored electrical energy, dew point temperature, and $\mathrm{CO}_{2}$ concentration indoors and merged using the Dempster-Shafer method of combining evidence. A hidden Markov method was then applied to predict the occupancy profile during the day. It is an evidence-based approach.

Wang and others, in [79], discuss a wireless sensor network (WSN) applied in the intelligent network communication system, which is low-cost, low-energy dissipation, self-organising, and highly flexible. This article presents WSN applications in condition-based maintenance, smart metering, and smart homes, among others.

Nguyen [86] makes a practical implementation of an intelligent home system based on a wireless sensor network for the integration of SGs. It presents a SG home gateway hardware design. The SG Home Gateway can control electrical devices according to the programming schedule or data received from the control centre. In addition, it proposes a simple wireless network topology based on the star routing protocol for the SG Home Network. The results of the final demonstration present a SG Home Gateway prototype.

It is interesting to note that the relationship between SGs, sensors, HAR, and ADL has multiple applications and different points of view, which are interrelated and have design and simulation perspectives that portend a very promising future for the benefit of people's health, even more so during this pandemic in which we have undergone lockdowns and where health and technology play an increasingly important role.

\section{Conclusions}

This work is approached with the main objective of analysing the existing literature in the most important scientific databases worldwide regarding the role played by SGs and their involvement in environments designed with sensors that fail to fully take into account people's quality of life. A study has been carried out that combines intelligent network technology, sensors, and environments inhabited by people in a multidisciplinary way.

At the beginning of the research we raised some questions that we will analyse in the conclusions:

1. Is the human vector taken into account in the design of SGs? How many of the sources consulted on SGs research take into account the Human-Technology binomial to implement architectures, designs, and installations that respect people's quality of life and their environment?

In response to this question and reviewing Table 8 , it can be seen that among the sources consulted that facilitate or consider the social and human condition in their work on SGs and the implementation of sensors, we found three sources that take into account the Human-Technology binomial in their research [61-63].

Most of the documents and work done in the field of SGs are approached from the point of view of the following patterns:

- Analysis of electrical and energy systems through intelligent devices.

- Studies of energy control systems in homes or smart environments.

- Basic research studies on architectures, mathematical models applied to the analysis of sensor data applied to SG infrastructures.

- Surveys and prototypes tested in laboratories or pilot houses. 
2. In the analysis of data from HAR and ADL systems and the use of sensors for their monitoring, are SG contributions being considered to adapt and improve data acquisition, management in monitoring activities, and implementation of the sustainable development goals and the energy transition?

According to the works analysed, in the search for literature on SGs and their relationship with the design and use of sensors in environments inhabited by people, they are closely related to energy aspects, mathematical models, data acquisition, etc. However, it is unusual to explore their relationship with HAR and ADL. This leads us to think that human needs, with their evolution and analysis, are not generally addressed from a transversal point of view in the generic field of SGs.

Indeed, studies on SGs are often linked with the fields of economics, business, and energy, whereas people and their daily needs are more often than not considered secondary. Of the more than 30,000 references obtained from the search on SGs in the WOS database, only one paper appears on ADL and it is related to the use of data collected from smart home monitoring devices for ADL recognition in order to use the results to establish a stochastic optimization problem for home energy storage management [88].

There is also a powerful source of citations, which addresses a review of the various fields of SG research, including health research, and provides a comprehensive overview of IoT with respect to architectures, enabling technologies, security and privacy issues, and presents the rationale for IoT and applications [89] (Figure 9).

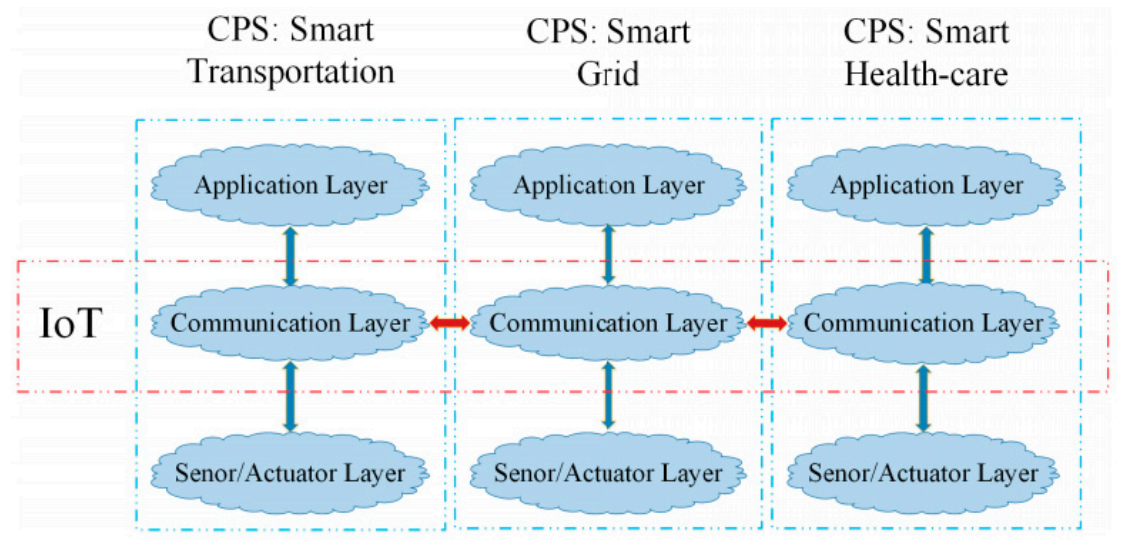

Figure 9. Integration of IoT and cyber-physical systems [89].

3. Are there synergies and multidisciplinary teams studying state-of-the-art technologies applied to environments inhabited by elderly or disabled people?

There are very broad and interesting teams and research related to the implementation of IoT technologies in SG networks applied to human environments, but they are very specific and sometimes only work in very specific environments. For example, they do not work on design for all people or design that can be used through generalised protocols in construction systems, electrical, electronic, and computer installation designs or multifunctional designs in homes or in installations in the service industries.

In the most relevant research with the greatest impact, which is reflected in Table 9, we find studies and analyses in which the parameters of SGs and HAR applied to human environments are interrelated, which can be implemented in environments inhabited by disabled or elderly people.

For example, in [35], a demand management model is developed to improve responses to the large amount of data and communications between energy suppliers and consumers, combining IoT technologies, sensors, and designs for more effective SGs. This research will directly improve human environments to streamline energy management. 
In [67], research was done into improving the environments inhabited by people, requiring SG connectivity, automation, and monitoring, which is achieved with the help of IoT. The IoT helps SG systems support various network functions throughout the generation, transmission, distribution, and consumption of energy by incorporating IoT devices (such as sensors, actuators, and smart meters), as well as providing connectivity, automation, and monitoring for those devices.

Similarly, design work was done in [37] to develop the technical skills of students, researchers, engineers, and faculties who want to address some of the problems faced by people around the world in the fields of smart sensors and IoT with applications in smart homes, smart cities, SGs, smart environments, smart transport, etc.

A study of older people in rural Scotland is presented in [61], where sensors were installed to measure electricity consumption and to show indoor and outdoor temperatures in the home. This is a specific case of application in older and/or disabled people.

In [43], a test bench for the intelligent home is presented based on the pedagogical model of project-based learning for undergraduate education, in which it is intended that students interrelate advances in SGs and its applications.

Likewise, we find studies with a very similar final goal, which is the analysis and evolution of SGs and applications to improve people's lives, such as in [44,52,55,63,90,91].

In conclusion, we have analysed numerous sources in which the main vector of information and analysis is the energy system, although it is true that in the institutional definitions of SGs and applied technologies there is great relevance to the energy indicator and more specifically to electricity, but we consider that within such a broad paradigm of study of SGs, there should be a greater emphasis on people, without merely relegating them to the fields of health, social sciences, or other disciplines outside the technological and engineering context.

If we involve the developers of SGs, such as engineers, technologists, and those in charge of the design, coordination, and implementation of energy, computer, and telecommunications facilities so that a more person-centric approach is achieved, it would be possible to create infrastructures that are structured transversally towards the Human-Technology binomial.

One of the most prestigious journals in the field of smart grid analysis is IEEE Transactions on Smart Grid, which deals with different studies on the subject. If we look for the term "human activities" in this publication, among the more than 130,000 documents, only one result appears [92]. In this case, it is a study that aims to reduce the energy consumption of people living at home.

It should be noted that most of the sources analysed in the databases correspond to conferences and a minority to journals. Most of the works referenced from the IEEExplore database, which has some degree of influence, are within the field of engineering.

A set of measures and an action protocol is thus proposed for SG research and its need for adaptation to humans, looking at integrating a greater involvement of the Human-Technology binomial and a better correlation with sustainable development goals in future works.

If we analyse the search that has been carried out on SGs and apply new search filters such as sustainable development goals and the Human vector, the result is even more disappointing, as it is limited to one publication out of 50,000 papers in the Scopus database alone [43]. It is curious that this work is carried out under the educational paradigm with an academic and non-business analysis.

In the different topics and research strategies analysed, depending on the database and the subject, the following references have been obtained as the most significant:

- $\quad$ SGs and their application to HAR and ADL.

- Simulation of intelligent environments with sensors in the home. Data control architecture, complex computer systems.

As indicated in the introduction to this paper, we conclude with the development of a protocol of recommendations for research on SGs and sensor design for human activities, taking into account sustainable development goals and measurement parameters for the energy transition and environmental protection (Figure 10). 


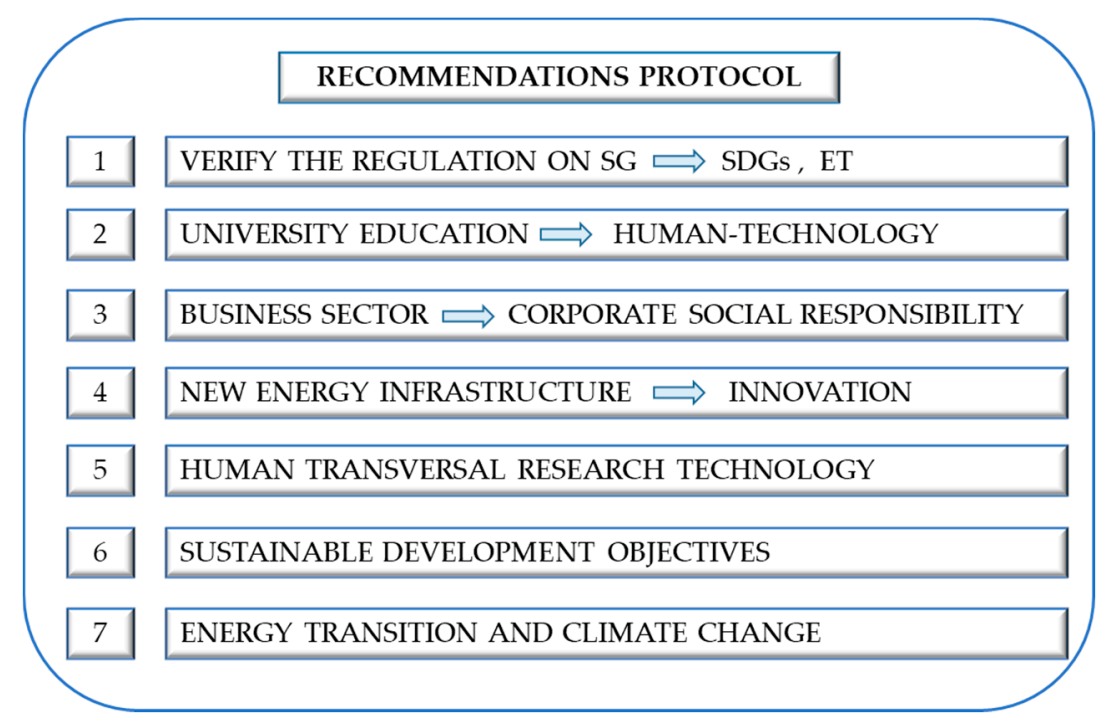

Figure 10. Protocol for Smart Grids (SGs), sensor, and Activities of Daily Living (ADL) research recommendations.

The following proposals for action are indicated for the implementation of projects and designs in intelligent environments with human activity at the core:

1. P1. The definitions and regulations on SGs should be structured according to sustainable development goals and the energy transition [93-95].

2. P2. Comprehensive training in universities and engineering and architecture schools should be based on the need to design and model in terms of the protection of human beings and their environment $[96,97]$.

3. P3. The technological and innovative business sector must be premised on corporate social responsibility based on the fact that production in intelligent systems with sensors and electrical networks must include people's needs and this ought to be the main parameter for design and construction. [98-100].

4. P4. The transition to SGs requires a new energy infrastructure along with various types of devices (e.g., electronic sensors and computer systems) throughout the electrical system, and their interconnection through high-speed communications networks using standardised protocols [101,102].

5. P5. The Human-Technology binomial must be integrated transversely in the design and technical developments in research on SGs with sensors applied to indoor environments.

6. P6. Sustainable development goals must be adapted and complied with in all intelligent network projects, taking into account their goals and objectives and offering technological solutions for compliance.

7. P7. Measures concerning the legal and regulatory aspects of the energy transition and the fight against climate change should also be considered transversally in future research and industrial applications involving SGs and sensors in human environments.

In this work, we have analysed different aspects of the research and studies carried out on SGs and the integration of sensors to improve people's quality of life and health, especially the most vulnerable, such as the elderly and disabled.

The technology that we design and build within intelligent environments must be a climate technology, efficient, human-centred, and which controls and measures consumption, reduces greenhouse gas emissions, prevents inappropriate consumption, and integrates energy efficiency and environmental sustainability processes. 


\section{Future Works}

In the future, we will work on the development and implementation of the recommendations protocol outlined in the conclusions of the work (Figure 10). We will focus our study on the monitoring of SGs for the energy transition and how this relates to sustainable development goals as a binding vector to achieve the path towards sustainability in the engineering and design of intelligent systems.

Author Contributions: Conceptualization, Á.V.-E., M.E.-E. and F.M.M.; literature review, Á.V.-E.; methodology, Á.V.-E., M.E.-E. and F.M.M.; formal analysis, Á.V.-E.; investigation, Á.V.-E., M.E.-E. and F.M.M.; supervision, M.E.-E.; validation, Á.V.-E., M.E.-E. and F.M.M. All authors have read and agreed to the published version of the manuscript.

Funding: The authors would like to thank funding under the REMIND project Marie Sklodowska-CurieEU Framework for Research and Innovation Horizon 2020, under grant agreement no. 734355, the Spanish Government by the project RTI2018-098979-A-I00 and Acción 1 of the University of Jaén under reference EI_TIC1_2019.

Conflicts of Interest: The authors declare no conflict of interest.

\section{References}

1. United Nations Climate Change. Report of the Green Climate Fund to the Conference of the Parties. Conference of the Parties. Technology Executive Committee (TEC). In Proceedings of the Twenty-Fifth Session, Madrid, Spain, 2-13 December 2019. Available online: https://unfccc.int/documents/210472 (accessed on 2 August 2020).

2. AENOR Standards. Standardisation in Intelligent Networks. Smart Grid-Application Specification. Interface and Framework for Customer. UNE-EN 50491-12-1:2019. Available online: https://www.aenor.com/ normas-y-libros/buscador-de-normas/une/?c=N0061386 (accessed on 2 August 2020).

3. De la Hoz Franco, E.; Ariza-Colpas, P.; Quero, J.M.; Espinilla, M. Sensor Based Datasets for Human Activity Recognition. A Systematic Review of Literature. IEEE Access 2018, 6, 59192-59210. [CrossRef]

4. Ma, Y.; Li, B. Hybridized Intelligent Home Renewable Energy Management System for Smart Grids. Sustainability 2020, 12, 2117. [CrossRef]

5. Li, Y. Design of a Key Establishment Protocol for Smart Home Energy Management System. In Proceedings of the 2013 Fifth International Conference on Computational Intelligence, Communication Systems and Networks, Madrid, Spain, 5-7 June 2013; pp. 88-93. [CrossRef]

6. Bolleddula, N.; Chun Hung, G.Y.; Ma, D.; Noorian, H.; Woodbridge, D.M. Sensor Selection for Activity Classification at Smart Home Environments. In Proceedings of the 42nd Annual International Conference of the IEEE Engineering in Medicine \& Biology Society (EMBC), Montreal, QC, Canada, 20-24 July 2020; pp. 3927-3930. [CrossRef]

7. Directive 2006/95/EC of the European Parliament and of the Council of 12 December 2006 on the Harmonisation of the Laws of Member States Relating to Electrical Equipment Designed for Use within Certain Voltage Limits. Available online: http://data.europa.eu/eli/dir/2006/95/oj (accessed on 5 August 2020).

8. Communication from the Commission to the European Parliament, the Council. The European Economic and Social Committee. A Digital Agenda for Europe. European Commission. EurLex-2010.DC0245. Available online: https://eur-lex.europa.eu/legal-content/EN/TXT/?uri=COM:2010:0245 (accessed on 6 August 2020).

9. UNE-EN ISO 16484-1:2011 Building Automation and Control Systems (BACS). Project Specification and Implementation (ISO 16484-1:2010). Available online: https://www.une.org (accessed on 6 August 2020).

10. UNE-EN 50491-5-2:2010 General Requirements for Home and Building Electronic Systems (HBES) and Building Automation and Control Systems (BACS). EMC requirements for HBES/BACS Used in Residential, Commercial and Light Industry Environment. Available online: https://www.une.org/encuentra-tu-norma/ busca-tu-norma/norma/?c=N0046285 (accessed on 7 August 2020).

11. Stojkoska, B.L.R.; Trivodaliev, K.V. A review of Internet of Things for smart home: Challenges and solutions. J. Clean. Prod. 2017, 140, 1454-1464. [CrossRef]

12. Wang, K.; Yu, J.; Yu, Y.; Qian, Y.; Zeng, D.; Guo, S.; Xiang, Y.; Wu, J. A Survey on Energy Internet: Architecture, Approach, and Emerging Technologies. IEEE Syst. J. 2018, 12, 2403-2416. [CrossRef]

13. Kitchenham, B.A.; Brereton, P. A systematic review of systematic review process in software engineering. Inf. Softw. Technol. 2013, 55, 2049-2075. [CrossRef] 
14. Kitchenham, B.; Brereton, P.; Budgen, D.; Turner, M.; Bailey, J.; Linkman, S. Systematic literature reviews in software engineering. A systematic literature review. Inf. Softw. Technol. 2009, 51, 7-15. [CrossRef]

15. Flórez, M. Casas inteligentes, hacia una definición. Inf. Constr. 2004, 56, 11-17.

16. David, M.; Koch, F. Smart Is Not Smart Enough! Anticipating Critical Raw Material Use in Smart City Concepts: The Example of Smart Grids. Sustainability 2019, 11, 4422. [CrossRef]

17. Bui, V.; Hussain, A.; Kim, H. A Multiagent-Based Hierarchical Energy Management Strategy for Multi-Microgrids Considering Adjustable Power and Demand Response. IEEE Trans. Smart Grid 2018, 9, 1323-1333. [CrossRef]

18. Cui, S.; Yu, Q.; Gu, G.; Gang, Q. Research on the architecture of electric power information communication network for smart grid. In Proceedings of the 2017 IEEE Conference on Energy Internet and Energy System Integration (EI2), Beijing, China, 26-28 November 2017; pp. 1-4.

19. Lee, M.A.; Nguyen, F.T.; Scott, K.; Chan, N.; Bakh, N.A.; Jones, K.; Strano, M.S. Implanted Nanosensors in Marine Organisms for Physiological Biologging: Design, Feasibility and Species Variability. ACS Sens. 2019, 4, 32-43. [CrossRef]

20. Saha, H.N.; Mandal, A.; Sinha, A. Recent trends in the Internet of Things. In Proceedings of the 2017 IEEE 7th Annual Computing and Communication Workshop and Conference (CCWC), Las Vegas, NV, USA, 9-11 January 2017; pp. 1-4.

21. Nahrstedt, K.; Li, H.; Nguyen, P.; Chang, S.; Vu, L. Internet of Mobile Things: Mobility-Driven Challenges, Designs and Implementations. In Proceedings of the 2016 IEEE First International Conference on Internet-of-Things Design and Implementation (IoTDI), Berlin, Germany, 4-8 April 2016; pp. 25-36.

22. Ayaz, M.; Ammad-uddin, M.; Baig, I.; Aggoune, M. Wireless Sensor's Civil Applications, Prototypes, and Future Integration Possibilities: A Review. IEEE Sens. J. 2018, 18, 4-30. [CrossRef]

23. Ahsan, U.; Bais, A. Distributed big data management in smart grid. In Proceedings of the 2017 26th Wireless and Optical Communication Conference (WOCC), Newark, NJ, USA, 7-8 April 2017; pp. 1-6.

24. Ahsan, U.; Bais, A. A Review on Big Data Analysis and Internet of Things. In Proceedings of the 2016 IEEE 13th International Conference on Mobile Ad Hoc and Sensor Systems (MASS), Brasilia, Brazil, 10-13 October 2016; pp. 325-330.

25. Wang, Y.; Liang, H.; Dinavahi, V. Two-stage stochastic demand response in smart grid considering random appliance usage patterns. IET Gener. Transm. Distrib. 2018, 12, 4163-4171. [CrossRef]

26. Hall, T.; Beecham, S.; Bowes, D.; Gray, D.; Counsell, S. A Systematic Literature Review on Fault Prediction Performance in Software Engineering. IEEE Trans. Softw. Eng. 2012, 38, 1276-1304. [CrossRef]

27. Conoscenti, M.; Vetro, A.; De Martin, J.C. Blockchain for the Internet of Things: A Systematic Literature Review. In Proceedings of the 2016 IEEE/ACS 13th International Conference of Computer Systems and Applications (AICCSA), Agadir, Morocco, 29 November-2 December 2016.

28. Neis, P.; Wehrmeister, M.A.; Mendes, M.F. Model Driven Software Engineering of Power Systems Applications: Literature Review and Trends. IEEE Access 2019, 7, 177761-177773. [CrossRef]

29. Missaoui, R.; Joumaa, H.; Ploix, S.; Bacha, S. Managing energy Smart Homes according to energy prices: Analysis of a Building Energy Management System. Energy Build. 2014, 71, 155-167. [CrossRef]

30. Jiang, L.; Liu, D.; Yang, B. Smart home research. In Proceedings of the 2004 International Conference on Machine Learning and Cybernetics (IEEE Cat. No.04EX826), Shanghai, China, 26-29 August 2004; Volume 2, pp. 659-663.

31. Ricquebourg, V.; Menga, D.; Durand, D.; Marhic, B.; Delahoche, L.; Loge, C. The Smart Home Concept: Our immediate future. In Proceedings of the 2006 1ST IEEE International Conference on E-Learning in Industrial Electronics, Hammamet, Tunisia, 18-20 December 2006; pp. 23-28.

32. Ramlee, R.A.; Othman, M.A.; Leong, M.H.; Ismail, M.M.; Ranjit, S. Smart home system using android application. In Proceedings of the 2013 International Conference of Information and Communication Technology (ICoICT), Bandung, Indonesia, 20-22 March 2013; pp. 277-280.

33. Muñoz Zuara, A.; Bruna Romero, J. Proyecto Smart City Málaga. Prototipo. Proyecto ZEM2ALL, Zero Emissions Mobillity to All. In Proceedings of the VI Congreso Smart Grids, Madrid, Spain, 16 December 2019.

34. Dileep, G. A survey on smart grid technologies and applications. Renew. Energy 2020, 146, $2589-2625$. [CrossRef]

35. Singh Aujla, G.; Garg, S.; Batra, S.; Kumar, N.; You, I.; Sharma, V. DROpS: A demand response optimization scheme in SDN-enabled smart energy ecosystem. Inf. Sci. 2019, 476, 453-473. [CrossRef] 
36. Ruzbahani, H.M.; Karimipour, H. Optimal incentive-based demand response management of smart households. In Proceedings of the 2018 IEEE/IAS 54th Industrial and Commercial Power Systems Technical Conference (I\&CPS), Niagara Falls, ON, Canada, 7-10 May 2018; pp. 1-7.

37. Islam, T.; Mukhopadhyay, S.C.; Suryadevara, N.K. Smart Sensors and Internet of Things: A Postgraduate Paper. IEEE Sens. J. 2017, 17, 577-584. [CrossRef]

38. Alharthi, A.S.; Yunas, S.U.; Ozanyan, K.B. Deep Learning for Monitoring of Human Gait: A Review. IEEE Sens. J. 2019, 19, 9575-9591. [CrossRef]

39. Maurya, A.; Akyurek, A.S.; Aksanli, B.; Rosing, T.S. Time-series clustering for data analysis in Smart Grid. In Proceedings of the 2016 IEEE International Conference on Smart Grid Communications (SmartGridComm), Sydney, Australia, 6-9 November 2016; pp. 606-611.

40. Vega, A.M.; Santamaria, F.; Rivas, E. Modeling for home electric energy management: A review. Renew. Sustain. Energy Rev. 2015, 52, 948-959. [CrossRef]

41. Samantaray, S.R. Editorial Special Issue on Sensors and Data analytics for Smart Grid Infrastructure. IET Gener. Transm. Distrib. 2015, 9, 113-114. [CrossRef]

42. Akula, P.; Mahmoud, M.; Akkaya, K.; Songi, M. Privacy-preserving and secure communication scheme for power injection in smart grid. In Proceedings of the 2015 IEEE International Conference on Smart Grid Communications (SmartGridComm), Miami, FL, USA, 2-5 November 2015; pp. 37-42.

43. Hu, Q.; Li, F.; Chen, C. A Smart Home Test Bed for Undergraduate Education to Bridge the Curriculum Gap from Traditional Power Systems to Modernized Smart Grids. IEEE Trans. Educ. 2015, 58, 32-38. [CrossRef]

44. Morello, R.; Mukhopadhyay, Z.; Slomovitz, D.; Samantaray, S.R. Advances on Sensing Technologies for Smart Cities and Power Grids: A Review. IEEE Sens. J. 2017, 17, 7596-7610. [CrossRef]

45. Collotta, M.; Pau, G. A Novel Energy Management Approach for Smart Homes Using Bluetooth Low Energy. IEEE J. Sel. Areas Commun. 2015, 33, 2988-2996. [CrossRef]

46. Bell, S.; Judson, E.; Bulkeley, H.; Powells, G.; Capova, K.A.; Lynch, D. Sociality and electricity in the United Kingdom: The influence of household dynamics on everyday consumption. Energy Res. Soc. Sci. 2015, 9, 98-106. [CrossRef]

47. Singaravelan, A.; Kowsalya, M. Design and Implementation of Standby Power Saving Smart Socket with Wireless Sensor Network. Procedia Comput. Sci. 2016, 92, 305-310. [CrossRef]

48. Völker, B.; Scholl, P.M.; Becker, B. Semi-Automatic Generation and Labeling of Training Data for Non-intrusive Load Monitoring. In Proceedings of the Tenth ACM International Conference on Future Energy Systems (e-Energy '19), Phoenix, AZ, USA, 25-28 June 2019; pp. 17-23. [CrossRef]

49. Jiang, J.; Qian, Y. Distributed communication architecture for smart grid applications. IEEE Commun. Mag. 2016, 54, 60-67. [CrossRef]

50. Wang, C.; Zhou, Y.; Wu, J.; Wang, J.; Zhang, Y.; Wang, D. Robust-Index Method for Household Load Scheduling Considering Uncertainties of Customer Behavior. IEEE Trans. Smart Grid 2015, 6, 1806-1818. [CrossRef]

51. Yu, H.; Shi, L.; Qian, Y.; Shu, F.; Li, J.; Zhao, Y.; Nalin, D.; Jayakody, K. A cooperative modulation recognition: New paradigm for power line networks in smart grid. Phys. Commun. 2017, 25, 268-276. [CrossRef]

52. Koutitas, G.C.; Tassiulas, L. Low Cost Disaggregation of Smart Meter Sensor Data. IEEE Sens. J. 2016, 16, 1665-1673. [CrossRef]

53. Stellios, I.; Kotzanikolaou, P.; Psarakis, M.; Alcaraz, C.; Lopez, J. A Survey of IoT-Enabled Cyberattacks: Assessing Attack Paths to Critical Infrastructures and Services. IEEE Commun. Surv. Tutor. 2018, 20, 3453-3495. [CrossRef]

54. Mosenia, A.; Sur-Kolay, S.; Raghunathan, A.; Jha, N.K. DISASTER: Dedicated Intelligent Security Attacks on Sensor-Triggered Emergency Responses. IEEE Trans. Multi Scale Comput. Syst. 2017, 3, 255-268. [CrossRef]

55. Javaid, N. An Intelligent Load Management System with Renewable Energy Integration for Smart Homes. IEEE Access 2017, 5, 13587-13600. [CrossRef]

56. Wazid, M.; Das, A.K.; Odelu, V.; Kumar, N.; Conti, M.; Jo, M. Design of Secure User Authenticated Key Management Protocol for Generic IoT Networks. IEEE Internet Things J. 2018, 5, 269-282. [CrossRef]

57. Ko, J.; Jeong, J.; Park, J.; Arm Jun, J.; Gnawali, O.; Paek, J. DualMOP-RPL: Supporting Multiple Modes of Downward Routing in a Single RPL Network. ACM Trans. Sens. Netw. 2015, 11, 2. [CrossRef] 
58. Fadel, E.; Faheem, M.; Gungor, V.C.; Nassef, L.; Akkari, N.; Malik, M.G.A.; Almasri, S.; Akyildiz, I.F. Spectrum-aware bio-inspired routing in cognitive radio sensor networks for smart grid applications. Comput. Commun. 2017, 101, 106-120. [CrossRef]

59. Peretti, G.; Lakkundi, V.; Zorzi, M. BlinkToSCoAP: An end-to-end security framework for the Internet of Things. In Proceedings of the 2015 7th International Conference on Communication Systems and Networks (COMSNETS), Bangalore, India, 6-10 January 2015; pp. 1-6. [CrossRef]

60. Jurado, S.; Nebot, A.; Mugica, F.; Mihaylov, M. Fuzzy inductive reasoning forecasting strategies able to cope with missing data: A smart grid application. Appl. Soft Comput. 2017, 51, 225-238. [CrossRef]

61. Barnicoat, G.; Danson, M. The ageing population and smart metering: A field study of householders' attitudes and behaviours towards energy use in Scotland. Energy Res. Soc. Sci. 2015, 9, 107-115. [CrossRef]

62. Spanò, E.; Niccolini, L.; Pascoli, S.D.; Iannacconeluca, G. Last-Meter Smart Grid Embedded in an Internet-of-Things Platform. IEEE Trans. Smart Grid 2015, 6, 468-476. [CrossRef]

63. Nag, A.; Mukhopadhyay, S.C.; Kosel, J. Wearable flexible sensors: A review. IEEE Sens. J. 2017, 17, 3949-3960. [CrossRef]

64. Manimuthu, A.; Ramesh, R. Privacy and data security for grid-connected home area network using Internet of Things. IET Netw. 2018, 7, 445-452. [CrossRef]

65. Arghandeh, R.; Von Meier, A.; Mehrmanesh, L.; Mili, L. On the definition of cyber-physical resilience in power systems. Renew. Sustain. Energy Rev. 2016, 58, 1060-1069. [CrossRef]

66. Raggett, D. COMPOSE: An Open Source Cloud-Based Scalable IoT Services Platform. ERCIM Nerws, 1 April 2015.

67. Saleem, Y.; Crespi, N.; Rehmani, M.H.; Copeland, R. Internet of Things-Aided Smart Grid: Technologies, Architectures, Applications, Prototypes, and Future Research Directions. IEEE Access 2019, 7, 62962-63003. [CrossRef]

68. Aroua, S.; El Korbi, I.; Ghamri-Doudane, Y.; Saidane, L.A. A distributed Cooperative Spectrum Resource Allocation in smart home cognitive wireless sensor networks. In Proceedings of the 2017 IEEE Symposium on Computers and Communications (ISCC), Heraklion, Crete, Greek, 3-6 July 2017; pp. 754-759.

69. Chen, B.; Kshirsagar, V.A.; Lo, S. Platform design for social Internet of Things. In Proceedings of the 2017 IEEE International Conference on Consumer Electronics (ICCE-TW), Taipei, Taiwan, 12-14 June 2017; pp. 67-68.

70. Frincu, M.; Draghici, R. Towards a scalable cloud enabled smart home automation architecture for demand response. In Proceedings of the 2016 IEEE PES Innovative Smart Grid Technologies Conference Europe (ISGT-Europe), Ljubljana, Slovenia, 9-12 October 2016; pp. 1-6.

71. Nachabe, L.; Girod-Genet, M.; El Hassan, B. Unified Data Model for Wireless Sensor Network. IEEE Sens. J. 2015, 15, 3657-3667. [CrossRef]

72. Kallitsis, M.G.; Michailidis, G.; Tout, S. Correlative monitoring for detection of false data injection attacks in smart grids. In Proceedings of the 2015 IEEE International Conference on Smart Grid Communications (SmartGridComm), Miami, FL, USA, 2-5 November 2015; pp. 386-391.

73. Taylor, R.; Baron, D.; Schmidt, D. The world in 2025-predictions for the next ten years. In Proceedings of the 2015 10th International Microsystems, Packaging, Assembly and Circuits Technology Conference (IMPACT), Taipei, Taiwan, 21-23 October 2015; pp. 192-195.

74. Ahsan, U.; Bais, A. Distributed Smart Home Architecture for Data Handling in Smart Grid. Can. J. Electr. Comput. Eng. 2018, 41, 17-27.

75. Nambi, S.N.A.U.; Prasad, R.V.; Lua, R.A. Decentralized Energy Demand Regulation in Smart Homes. IEEE Trans. Green Commun. Netw. 2017, 1, 372-380. [CrossRef]

76. Ma, S.; Liu, Q.; Sheu, P.C. Foglight: Visible Light-Enabled Indoor Localization System for Low-Power IoT Devices. IEEE Internet Things J. 2018, 5, 175-185. [CrossRef]

77. Collotta, M.; Pau, G. An Innovative Approach for Forecasting of Energy Requirements to Improve a Smart Home Management System Based on BLE. IEEE Trans. Green Commun. Netw. 2017, 1, 112-120. [CrossRef]

78. Borkar, S.G.; Pande, H. Application of 5G next generation network to Internet of Things. In Proceedings of the 2016 International Conference on Internet of Things and Applications (IoTA), Pune, India, 22-24 January 2016; pp. 443-447. [CrossRef]

79. Cetinkaya, O.; Akan, O.B. Electric-Field Energy Harvesting in Wireless Networks. IEEE Wirel. Commun. 2017, 24, 34-41. [CrossRef] 
80. Wu, X.; Zhu, H. A Calculus for Wireless Sensor Networks from Quality Perspective. In Proceedings of the 2015 IEEE 16th International Symposium on High Assurance Systems Engineering, Daytona Beach Shores, FL, USA, 8-10 January 2015; pp. 223-231.

81. Kühn, E. Reusable Coordination Components: Reliable Development of Cooperative Information Systems. Int. J. Coop. Inf. Syst. 2016, 25, 1740001. [CrossRef]

82. Viswanathan, A.; Sai Shibu, N.B.; Rao, S.N.; Ramesh, M.V. Security Challenges in the Integration of IoT with WSN for Smart Grid Applications. In Proceedings of the 2017 IEEE International Conference on Computational Intelligence and Computing Research (ICCIC), Coimbatore, India, 14-16 December 2017; pp. 1-4.

83. Knirsch, F.; Engel, D.; Frincu, M.; Prasanna, V. Model-based assessment for balancing privacy requirements and operational capabilities in the smart grid. In Proceedings of the IEEE Power \& Energy Society Innovative Smart Grid Technologies Conference (ISGT), Washington, DC, USA, 18-20 February 2015; pp. 1-5.

84. Chaney, J.; Hugh Owens, E.; Peacock, A.D. An evidence based approach to determining residential occupancy and its role in demand response management. Energy Build. 2016, 125, 254-266. [CrossRef]

85. Wang, P.; Hou, H.; He, X.; Wang, C.; Xu, T.; Li, Y. Survey on Application of Wireless Sensor Network in Smart grid. Procedia Comput. Sci. 2015, 52, 1212-1217. [CrossRef]

86. Nguyen, M.; Nguyen, L.; Nguyen, T. A practical implementation of wireless sensor network based smart home system for smart grid integration. In Proceedings of the 2015 International Conference on Advanced Technologies for Communications (ATC), Ho Chi Minh City, Vietnam, 14-16 October 2015; pp. 604-609.

87. Wang, P.; He, J.; Xu, L.; Wu, Y.; Xu, C.; Zhang, X. Characteristic Modeling of TOA Ranging Error in Rotating Anchor-Based Relative Positioning. IEEE Sens. J. 2017, 17, 7945-7953. [CrossRef]

88. Zhuang, P.; Liang, H. Energy storage management in smart homes based on resident activity of daily life recognition. In Proceedings of the 2015 IEEE International Conference on Smart Grid Communications (SmartGridComm), Miami, FL, USA, 2-5 November 2015; pp. 641-646.

89. Lin, J.; Yu, W.; Zhang, N.; Yang, X.; Zhang, H.; Zhao, W. A Survey on Internet of Things: Architecture, Enabling Technologies, Security and Privacy, and Applications. IEEE Internet Things J. 2017, 4, 1125-1142. [CrossRef]

90. Chen, Y.; Martínez-Ortega, J.; Castillejo, P.; López, L. A Homomorphic-Based Multiple Data Aggregation Scheme for Smart Grid. IEEE Sens. J. 2019, 19, 3921-3929. [CrossRef]

91. Yu, T.; Ren, W.; Nahrstedt, K. MMLOC: Multi-mode indoor localization system based on smart access points. In Proceedings of the 16th EAI International Conference on Mobile and Ubiquitous Systems: Computing, Networking and Services, MobiQuitous 2019, Houston, TX, USA, 12-14 November 2019; pp. 473-482. [CrossRef]

92. Hu, Q.; Li, F. Hardware Design of Smart Home Energy Management System with Dynamic Price Response. IEEE Trans. Smart Grid 2013, 4, 1878-1887. [CrossRef]

93. International Electrotechnical Commission (IEC). Smart Grids Standards Map. Available online: http: //smartgridstandardsmap.com/ (accessed on 10 August 2020).

94. European Commsission. Directorate General for Energy. Standardization Mandate to European Standardisation Organisations (ESOs) to Support European Smart Grid Deployment. Available online: https://ec.europa.eu/energy/sites/ener/files/documents/2011_03_01_mandate_m490_en.pdf (accessed on 11 August 2020).

95. Lacal-Arantegu, R.; Jäger-Waldau, A. Technology Map of the European Strategic Energy Technology Plan (SET-Plan); JRC 86357/EUR 26345 EN; Publications Office of the European Union: Luxembourg, 2013.

96. Konstantinou, G.; Yusuf, M. Smart Grid Education: A Review of Global Course Offerings and the UNSW Sydney Approach. In Proceedings of the 2018 IEEE International Conference on Teaching, Assessment, and Learning for Engineering (TALE), Wollongong, Australia, 4-7 December 2018; pp. 850-854.

97. Ponce, P.; Ibarra, L.; Mata, O.; Molina, A. How to develop research skills among undergraduate engineering students to tackle current ongoing topics? A Smart-Grid case study. Int. J. Electr. Eng. Educ. 2019. [CrossRef]

98. Makienko, M.A.; Kurkan, N.V.; Emelyanenko, E.E. Ethical Implications to the Assessment of the Smart Grid Technology in Russia. In Proceedings of the MATEC Web of Conferences, Tomsk, Russia, 10-14 October 2016; Volume 912017, p. 1020. [CrossRef] 
99. Carbajo, R.; Cabeza, L.F. Renewable energy research and technologies through responsible research and innovation looking glass: Reflexions, theoretical approaches and contemporary discourses. Appl. Energy 2018, 211, 792-808. [CrossRef]

100. McLean, A.; Bulkeley, H.; Crang, M. Negotiating the urban smart grid: Socio-technical experimentation in the city of Austin. Urban Stud. 2016, 53, 3246-3263. [CrossRef]

101. Waseem Ahmad, M.; Mourshed, M.; Mundow, D.; Sisinni, M.; Rezgui, Y. Building energy metering and environmental monitoring. A state of the art review and directions for future research. Energy Build. 2016, 120, 85-102. [CrossRef]

102. Mylrea, M. Smart energy-internet-of-things opportunities require smart treatment of legal, privacy and cybersecurity challenges. J. World Energy Law Bus. 2017, 10, 147-158. [CrossRef]

Publisher's Note: MDPI stays neutral with regard to jurisdictional claims in published maps and institutional affiliations.

(C) 2020 by the authors. Licensee MDPI, Basel, Switzerland. This article is an open access article distributed under the terms and conditions of the Creative Commons Attribution (CC BY) license (http://creativecommons.org/licenses/by/4.0/). 